Journal of Economics and Behavioral Studies

Vol. 1, No. 1, pp. 9-19, Dec 2010.

\title{
Investigating Expiration Day Effects in Stock Index Futures in India
}

\author{
Sathya Swaroop Debasish \\ Reader, P.G.Department of Business Administration \\ Utkal University, Vani Vihar, Bhubaneswar-4, Orissa, India \\ sathyaswaroop2000@yahoo.com
}

\begin{abstract}
This study attempts to examine whether potential expiration effects exist on the NSE Nifty index by comparing the trading volume and return process at expiration with a comparison group. The period of analysis covers index futures expirations from June 2001 to May 2009. The trading volume and return process on expiration days and during expiration weeks were compared with a set of comparison days and comparison weeks. The current study used the pooled $t$-test and Wilcoxon rank sum test to investigate whether mean returns, price ranges, and adjusted trading volumes (i.e. time-independent trading volumes) were significantly different at expiration. The procedure as used by Stoll and Whaley (1987) was used to examine if price reversals existed during expiration days and comparison days.The evidence indicates that the trading volume on expiration days and in expiration weeks was significantly larger than on comparison days and during comparison weeks. Further, the results suggest that there were no price distortions on the expiration day or during the expiration week for the complete sample period and the second sub-period. For the first sub-period, however, evidence suggesting that expiration days and weeks experienced higher volatility than normal does exist. No evidence of significantly different mean returns, volatility, or price reversals at expiration was found. This could be due to the longer settlement period in India. However, when the complete sample period was divided into two sub-periods it was found that expiration day (weeks) during the first sub period may have experienced price distortions. The results of this study are crucial to investors, stock exchange officials, and regulators.
\end{abstract}

Keywords: Futures, Stock Index, Expiration day, NSE Nifty, Price reversal

\section{Introduction}

The Indian capital market has witnessed a major transformation and structural change from the past one decade as a result of ongoing financial sector reforms initiated by the Government of India. One of the major objectives of these reforms was to bring the Indian capital market up to a certain international standard. Due to such reforming process, one of the significant step taken in the secondary market is the introduction of derivative products in two major Indian stock exchanges viz. National Stock Exchange (NSE) and Bombay Stock Exchange (BSE) , with a view to provide tools for risk management to investors and to improve the informational efficiency of the cash market. Though the onset of derivative trading has significantly altered the movement of stock prices in Indian spot market, it is yet to be proved whether the derivative products have served the purpose as claimed by the Indian regulators.

Introduction of financial derivatives like index futures is considered to be one of the most important financial innovations that have taken place in the sphere of financial market in the last few decades. The primary objective of such a structural change in the financial market is to contain the risk involved in the financial investment strategies. The National Stock Exchange (NSE) of India has introduced a variety of financial derivatives to keep pace with rest of the world in maintaining efficiency and quality of the financial market. The stock future was introduced for trading in the NSE on November 9, 2001 on a limited number of common shares. One of the significant areas for empirical investigation in stock market dynamics is the existence of expiration day effect and its impact on underlying spot market. Expiration day effects may arise from stock index arbitrageurs unwinding of arbitrage positions in the stock market. While the cash settlement feature used for index derivatives allows derivative positions to be self-liquidated, stock positions must be liquidated through trades in the marketplace. If many arbitrageurs liquidate at the same time and in the same 
direction, price effects are possible. Another possible source for expiration day price effects is deliberate attempts to manipulate prices.

The expiration day effect may be defined as the effect on securities prices and volume as traders adjust their positions shortly before expiration of options and futures contracts. The expiration day effect may arise from several sources (Stoll and Whaley, 1997). One is from the arbitrageurs who unwind arbitrage positions in the stock market due to the deviation of the futures price from its fair value stipulated by the cost-of-carry relationship. If many arbitrageurs liquidate at the same time and in the same direction, price effects are possible. However, this strategy termed as cash-and-carry arbitrage make sense only when the cost involved is less than the arbitrage profit. The market price manipulation is another source of expiration day effect. The investors with positions in the futures market may have concerns with respect to the settlement price and will try to manipulate the underlying market price in a favorable direction.

The stock market procedure also leads to the expiration day effects. The severity of price effects on expiration day depends in part on the stock market procedures for accommodating order imbalances that may arise when arbitrage positions are unwound. If the underlying market for the index stocks is deep and if suppliers of liquidity are quick to respond to selling or buying pressure, the price effects of large arbitrage unwinding will be small. If unjustified price effects were known to occur, knowledgeable investors would stand ready to buy under priced stocks and sell overpriced stocksactions that would normally limit price effects to fall within the bounds of transaction costs. If market mechanisms are not well designed to offset sudden imbalances, however, the price effects may be substantial. In the case of index futures contracts that settle at the close, arbitrage positions must be unwound at closing prices.

In this paper, the last trading day is referred to as the "expiration day" since it is this day's prices that determine the settlement price. Because unwinding is expected to take place throughout the expiration day, this study uses daily data. By its very nature, arbitrage between the cash and (especially) futures markets require investors to unwind positions in the latter market on the day of expiration of contracts, in order to realize arbitrage profits. The consequent increase in the number of large buy and sell orders, and the temporary mismatch between these orders, can significant affect prices and volatility in the underlying cash market. Not surprisingly, regulators around the world have responded with a number of measures aimed at reducing price volatility on account of the socalled expiration effect of index derivatives. The importance of expiration day effects on the cash market to regulators has, in turn, generated interest on such effects within the research community.

\section{Objectives of the Study}

Though there have been numerous studies on developed country futures markets, there have been few in-depth studies of such markets in emerging countries such as India. The objectives of the study are:

1. Investigate the extent of trading volume at expiration day/expiration week as compared to comparison group.

2. To find whether the mean return at expiation day/week is significantly different from that of comparison group.

3. To compare the standard deviation of stock returns at expiration as against that of a comparison group.

4. To find whether the daily price range at expiation is significantly different from that of comparison group.

5. To investigate whether price reversal on days following expiration day/ expiration week is different than for the comparison group.

\section{Literature Review}

The empirical literature pertaining to the impact of expiration day of financial derivatives (both options and futures) on stock market related to national and international market are quite limited. The main source of concern regarding expiration day effects of index derivatives arises from the cash settlement. Several authors have tested for unusual volatility in the underlying markets on days 
when derivatives expire. Expiration day effects in the United States have been examined by Stoll and Whaley (1990), Edwards (1988) and Herbst and Maberly (1990). Pope and Yadav (1992) reported evidence of expiration day effect for individual stock options in the U.K. Evidence of an expiration day effect on underlying market volatility appears mixed. Where an effect has been found, it appears mostly temporary and small in magnitude. Several studies have examined triple witching days in the US market. Stoll and Whaley (1987) and Edwards (1988) find no evidence of increased stock market volatility on futures expiration days. Bacha and Villa (1993) arrive at similar results for the Nikkei stock and futures contracts. They find no evidence of an expiration day effect on the underlying Nikkei Index in Tokyo. They point out that these could be due to the staggered expiration dates and the use of different final settlement prices.

A number of empirical studies investigating simultaneous expiration of index futures and options have been published focusing on changes in trading volume, volatility, mean return, and price reversals at and around expiration. The impact from expirations on the trading volume of the underlying market has been examined by Stoll and Whaley (1987), Chamberlain et al. (1989), Karolyi (1996), and Stoll and Whaley (1997). The last two of these studies report significantly higher volumes at expiration than on non-expiration days. Stoll and Whaley (1987) show that the trading volume was $8 \%$ higher on expiration days than on non-expiration days, but no significance test is reported. Schlag (1996) reports significant increases in trading volume for both index futures and options expirations, while Karolyi (1996) only reports significant increases at index futures expirations. A study made by Chuang (2003) examined the impact of the expiration of Hang Sang Index derivatives on the underlying cash market in Hong Kong for the period 1990-1999. Employing comparison-period approach, the empirical findings indicated that expiration days in Hong Kong might be associated with a negative price effect and some return volatility on the underlying stock market, but there was no evidence of abnormal trading volume on the expiration days. Illueca and Lafuente (2006) explored additional evidence on expiration effects in the Ibex 35 stock index futures market using realized volatility model. Their findings revealed not only a significant increase in spot trading activity, but also the existence of a significant jump in spot volatility at index futures expiration. Moreover, they analyzed the importance of the data frequency considered, revealing that the use of GARCH methodology from daily data did not have the ability to statistically assess such expiration-day effect. Additional empirical evidence was provided for the S\&P 500 stock index futures market. Neither unconditional nor conditional realized volatility had a significant increase at expiration for the US market, suggesting that this effect was specific for the Spanish market, at least for the period analyzed.

In the Indian scenario, there have been few studies on impact of expiration day on the underlying stock market. Thenmozhi and Sony (2004) analyzed the effect of expiration days on Nifty index derivatives using the GARCH technique. Using the data from 2000 to 2003, the study concluded that on expiration days, there was a significant increase in the volatility but there was a relatively substantial decrease in volatility during the expiration weeks compared to non-expiration weeks. Vipul (2005) uses data on 14 equity shares to examine expiration day effects in the Indian stock market. The underlying stocks are selected in a manner that reflected a range of different liquidities for the associated derivative products; the ratio of turnover in the derivatives market to turnover in the underlying cash market ranged from 55 percent to 344 percent. Thereafter, the price, volatility and volume of the underlying shares in the cash segment of the exchange 1 day prior to expiration (of derivatives contracts), on the day of expiration and 1 day after expiration are compared with the corresponding values of these variables 1 week and 2 weeks prior to the expiration days, using the Wilcoxon matched-pairs signed-rank test. The study concludes that prices in the cash market are somewhat depressed a day before the expiration of the derivatives contracts, and they strengthen significantly the day after the expiration. However, for most of the shares, this does not tantamount to price reversals. Finally, volumes are higher on expiration days than on the benchmark nonexpiration days.

Jindal and Bodla (2007) analyzed the effect of expiration of stock derivatives on the volatility, return and trading volume of underlying individual stocks listed on National Stock Exchange (NSE). The results from the sample period showed the presence of an abnormally high trading volume on expiration day, thereby suggesting that arbitrage and manipulating activities take place in the market 
and that positions are unwound at the expiration. Hence, there was a greater volatility in the market on the expiration day. However, the unwinding of arbitrage positions failed to cause any significant price distortion at expiration, as there is no significant change in the return on stocks on the expiration day. Maniar, Bhatt and Maniyar (2007) studied the effect of expiration day of the Index futures and Options on the trading volume, variance and price of the underlying shares using a GARCH (Generalized Auto Regressive Conditional Heteroskedastic) framework. The impact of derivatives trading on the underlying stock market has been widely documented in the Finance literature. In particular, significant differences in the statistical properties of asset returns (for instance, mean and variance) during expiration and non-expiration days have been advanced as an evidence for the destabilization effect (or lack there of) of derivative instruments. They used both daily and high frequency (5 minutes and 10 minutes) data on S\&P CNX Nifty Index. The central finding using intra-day data was that while there is no pressure - downward or upward - on index returns, the volatility was indeed significantly affected by the expiration of contracts. This effect, however, did not showed up in daily data. Bodla and Kiran (2008) attempted to investigate the impact of equity derivatives on the trading volume of underlying Indian stock market. Their study found a positive impact of expiration of derivatives on trading volume of sample stocks. For this purpose, the daily traded value data of cash market and 22 individual stocks were collected and analyzed by using before-and-after control sample technique. The results of the study also showed that Compound Annual Growth Rate (CAGR) of trading volume had declined slightly after the introduction of derivatives.

\section{Research Methodology}

High frequency data for the NSE Nifty stock index futures is obtained from the NSE Research \& Publication wing on CD-ROM, which contains information on the time to the nearest second, contract type, stock/ index code, delivery month, price, transaction code (bid, ask or trade), and traded volume. The study had used two most popular statistical software packages for analysis, namely SPSS 11.5 version and Eviews 3.0.

The current study investigates the effects of index futures expiration on the Indian NSE Nifty index. At expiration, the settlement price for the NSE Nifty index is set to the average volume-weighted value of the last trading day. The period of analysis covers index futures expirations from June 2000 to May 2009. The trading volume and return process on expiration days and during expiration weeks were compared with a set of comparison days and comparison weeks. The expiration week was investigated to examine possible effects from early unwinding. The rationale for investigating the expiration week is that one solution for limiting the settlement risk, partly induced by the longer settlement period, is to close the arbitrage position before expiration, which in turn may result in price and volume effects prior to the expiration day. Merrick (1989), Brennan and Schwartz (1990), and Cheng et al. (1998) show that the early closing out of arbitrage positions, in general, could be an important determinant in generating arbitrage profits. In addition, Merrick (1989) points out that if the realized price pattern makes early unwinding unfavorable the arbitrageur can delay the unwinding by contract rollovers until it becomes favorable, and discusses the impact of contract rollovers on expiration day unwinding.

The following five hypotheses are tested for the expiration day:

H1: The trading volume at expiration is not higher than for the comparison group.

$\mathrm{H} 2$ : The mean return at expiration is not different than for the comparison groups.

H3: The standard deviation of stock returns at expiration is not higher than for the comparison group.

H4: The daily price range at expiration is not greater than for the comparison group.

H5: The price reversal on days following expiration days is not greater than for the comparison group.

Hypothesis $\mathrm{H} 1, \mathrm{H} 2, \mathrm{H} 3$, and $\mathrm{H} 4$ are also examined for the expiration week. The expiration week was defined as the three days before the expiration day. 
To evaluate whether the regulatory changes resulted in any differences in arbitrage trading, the entire sample period was divided in two sub-periods, from June 2001 to May 2005, and from June 2005 to May 2009. The latter sub-period was characterized by a more mature derivatives market than the first sub-period, which suggests a different trading behavior for each of the two sub-periods. The first and second week of each month were used as the comparison group. At NSE, stock futures and options expire on the last Thursday of each month, which is the rationale for not including this week in the comparison group. This was also the reason for only using three days before the expiration day as the "expiration week," as an extension of the period would include any potential expiration effects arising from stock futures and option expirations.

Returns estimated as close-to-close returns computed using the natural logarithm of relative prices and its standard deviation was used as an estimator of stock return volatility. The daily price range was estimated by taking the natural logarithm of the daily high divided by the daily low, and motivated by the close-to-close returns' inability to reflect price distortions that are reversed before the close. This estimator is similar to Schwert's (1990) high-low spread and its efficiency, as a volatility estimator, is supported by the results of Parkinson (1980) and Wiggins (1992). The reason for using daily observations was that unwinding is expected throughout the expiration day.

The current study used the pooled $t$-test to investigate whether mean returns, price ranges, and adjusted trading volumes (i.e. time-independent trading volumes) were significantly different at expiration. Because the time series were found to be non-normally distributed the non-parametric Wilcoxon rank sum test (W-test) was also used. Since the $t$-test and the Wilcoxon rank sum test provided somewhat different results for the price range and the adjusted trading volume, the results pertaining to the Wilcoxon rank sum test is also presented for these two variables. The Wilcoxon signed-rank test is a non-parametric statistical hypothesis test for the case of two related samples or repeated measurements on a single sample. It can be used as an alternative to the paired Student's ttest when the population cannot be assumed to be normally distributed. The test is named for Frank Wilcoxon (1892-1965) who, in a single paper, proposed both it and the rank-sum test for two independent samples (Wilcoxon, 1945).Like the t-test, the Wilcoxon test involves comparisons of differences between measurements, so it requires that the data are measured at an interval level of measurement. However it does not require assumptions about the form of the distribution of the measurements. It should therefore be used whenever the distributional assumptions that underlie the t-test cannot be satisfied. Further, to examine if price reversals existed, the study has employed the same procedure as used by Stoll and Whaley (1987), and Chamberlain et al. (1989). The Price reversal test may be used under the axiomatic approach which requires that the quantity index remains unchanged after the price vectors for the two periods being compared are interchanged.

A price reversal was estimated according to the following three definitions:

Type 0,

$\mathrm{REV}_{0 \mathrm{t}}=\mathrm{R}_{\mathrm{t}+1}$ if $\mathrm{R}_{\mathrm{t}}<0$

$\mathrm{REV}_{0 \mathrm{t}}=-\mathrm{R}_{\mathrm{t}+1}$ if $\mathrm{R}_{\mathrm{t}} \geq 0$

where $R_{t}$ is the return during the expiration day and $R_{t+1}$ is the return on the subsequent day. A positive value for REV0t indicates a price reversal, while a negative value indicates a continuation.

Type 1,

$\mathrm{REV}_{1 \mathrm{t}}=|\mathrm{Rt}+1|$ if $\operatorname{sign}\left(\mathrm{R}_{\mathrm{t}}\right) \neq \operatorname{sign}\left(\mathrm{R}_{\mathrm{t}+1}\right)$

$\mathrm{REV}_{1 \mathrm{t}}=0$ otherwise

where $R E V_{1 t}$ is given a value of 0 when $R_{t}$ and $R_{t+1}$ are of the same sign, while $R E V_{0 t}$ would have a negative value.

Type 2,

$\mathrm{REV}_{2 \mathrm{t}}=|\mathrm{Rt}|$ if $\operatorname{sign}(\mathrm{Rt}) \neq \operatorname{sign}(\mathrm{Rt}+1)$

$\mathrm{REV}_{2 \mathrm{t}}=0$ otherwise.

The type 1 and 2 definitions tend to overestimate return reversals "because price reversals due to new information (unrelated to expiration) are fully reflected, whereas the failure of prices to reverse 
because of new information is not reflected," according to Stoll and Whaley (1987). The type 2 definition, in contrast to the other two, is based on the price change that occurs on the expiration day. However, since there was no theoretical ground for using a particular definition of reversal, the present study employs all the above three definitions.

\section{Analysis and Findings}

\subsection{Trading Volume Effects}

Table 1 gives the daily adjusted trading volume for NSE Nifty index stocks by proving details of mean, standard deviation, median, t-test and W-test. Panel A presents these statistical details for expiration days, while panel B presents that for the expiration week. For the entire time period of June 2001 to May 2009 on the average, the adjusted trading volume was 5.9\% higher (in terms of expiration day as shown in panel-A) and 6.3\% (in terms of expiration week as shown in panel-B). Thus, the mean of trading volume is higher for expiration group as against the comparison group. Similar observation is found for median of trading volume at NSE Nifty index. The two sub-periods also showed similar findings with mean and median being relatively higher in expiration group than the comparison group. For the first sub-period (June 2001 to May 2005), expiration days experienced $\mathbf{9 . 0 9 \%}$ higher trading volumes than comparison days (panel-A).

Table -1: Daily adjusted trading volume for the stocks that comprise the NSE Nifty Index

\begin{tabular}{|c|c|c|c|c|c|}
\hline \multirow{2}{*}{ Period } & \multirow{2}{*}{ Statistic } & \multicolumn{2}{|c|}{ Panel A: Expiration days } & \multicolumn{2}{|c|}{ Panel B: Expiration weeks } \\
\hline & & $\begin{array}{l}\text { Expiration } \\
\text { group }\end{array}$ & $\begin{array}{c}\text { Comparison } \\
\text { group }\end{array}$ & $\begin{array}{l}\text { Expiration } \\
\text { group }\end{array}$ & $\begin{array}{c}\text { Comparison } \\
\text { group }\end{array}$ \\
\hline \multirow{7}{*}{$\begin{array}{l}\text { June } 2001 \\
\text { to } \quad \text { May } \\
2009 \\
\text { June } 2001\end{array}$} & Number of days & 108 & 216 & 324 & 854 \\
\hline & Mean & 1.041 & 0.983 & 0.981 & 0.922 \\
\hline & Standard deviation & 0.511 & 0.562 & 0.482 & 0.525 \\
\hline & Median & 0.932 & 0.859 & 0.938 & 0.862 \\
\hline & $t$-test & \multicolumn{2}{|c|}{$2.19 *$} & \multicolumn{2}{|c|}{$2.17^{*}$} \\
\hline & $\mathrm{W}$-test & \multicolumn{2}{|c|}{$2.41^{*}$} & \multicolumn{2}{|c|}{$2.63^{*}$} \\
\hline & Number of days & 54 & 108 & 162 & 427 \\
\hline to May & Mean & 0.852 & 0.781 & 0.873 & 0.786 \\
\hline \multirow[t]{6}{*}{2005} & Standard deviation & 0.324 & 0.426 & 0.502 & 0.431 \\
\hline & Median & 0.812 & 0.753 & 0.863 & 0.801 \\
\hline & $t$-test & \multicolumn{2}{|c|}{$1.23^{*}$} & \multicolumn{2}{|c|}{$1.76^{*}$} \\
\hline & W-test & \multicolumn{2}{|c|}{$2.09^{*}$} & \multicolumn{2}{|c|}{$2.15^{*}$} \\
\hline & Number of days & 54 & 108 & 162 & 427 \\
\hline & Mean & 1.124 & 1.087 & 1.119 & 1.108 \\
\hline \multirow{4}{*}{$\begin{array}{ll}\text { June } & 2005 \\
\text { to } & \text { May } \\
2009 & \end{array}$} & Standard deviation & 0.436 & 0.429 & 0.415 & 0.483 \\
\hline & Median & 1.142 & 0.991 & 1.051 & 0.936 \\
\hline & $t$-test & \multicolumn{2}{|c|}{1.69} & \multicolumn{2}{|c|}{1.77} \\
\hline & $\mathrm{W}$-test & \multicolumn{2}{|c|}{2.01} & \multicolumn{2}{|c|}{1.91} \\
\hline
\end{tabular}

Note: The terms "Mean" and "Median" denote open-to-close mean and median adjusted trading volume, respectively. The term "Standard deviation" denotes the standard deviation of open-to-close adjusted trading volume.

* indicates that a one-sided pooled $\boldsymbol{t}$-test or Wilcoxon rank sum test (W-test) is able to reject the hypothesis that the daily trading volume at expiration is not higher than for the comparison group at the $5 \%$ level of significance.

The result of the one-sided pooled $t$-test and the Wilcoxon rank sum test suggests that trading volumes were significantly higher at expiration and the differences are statistically significant. The data for the second sub-period (i.e. June 2005 to May 2009) show that mean trading volumes on days when index futures and options expired were $3.47 \%$ higher than on other days, but this difference was not found to be statistically significant. Thus, the results of the one-sided pooled $t$-test and Wilcoxon rank sum test show that the difference in the daily trading volume is statistically significant, at the 5\% level for the entire period and initial sub-period (June 2001 to May 2005). But, there was no significant difference in the daily trading volume for the latter sub-period (June 2005 to May 2009) as shown from the insignificant t-test and W-test values. 
Panel B, in Table 1, contains the same statistics as panel A, but for expiration and comparison weeks, rather than days. It is noteworthy that the adjusted trading volume was significantly higher for expiration weeks than for comparison weeks for the entire sample period as well as for the two subperiods investigated. To conclude, the evidence of significantly higher trading volumes for expiration days than for comparison days suggests that arbitrage activity occurred and that arbitrage positions remained to be unwound on the expiration day. However, the finding that the expiration weeks were characterized by higher trading volumes than the other weeks suggests that an early unwinding of arbitrage positions also occurred during the sample period. Consequently, price distortions may have occurred on the expiration day and during the expiration week for the investigated sample period.

\subsection{Return and Volatility Effects}

Panel A, in Table 2, summarizes the mean and median daily return and volatility (measured by the standard deviation) for the NSE Nifty index on expiration and comparison days. For the complete sample period, the average daily return for expiration days was $17.3 \%$ higher than that of comparison days. The two sided pooled $t$-test and $W$-test supports the hypothesis of no difference between the two samples. The fact that short selling was prohibited during almost the entire first sub-period implies that reverse positions on the NSE Nifty should have been non-existent or at least uncommon. For the first sub-period (June 2001 to May 2005), expiration days experienced 2.19\% higher trading volumes than comparison days. The result of the one-sided pooled $t$-test and the Wilcoxon rank sum test suggests that trading volumes were significantly higher at expiration and the differences are statistically significant at $5 \%$ level. The data for the second sub-period (i.e. June 2005 to May 2009) show that mean trading volumes on days when index futures and options expired were $15.17 \%$ higher than on other days, and this difference was found to be statistically significant at $5 \%$ level, both in terms of t-test and W-test.

Table -2: Daily returns and standard deviation for the NSE Nifty Index

\begin{tabular}{|c|c|c|c|c|c|}
\hline \multirow{2}{*}{ Period } & \multirow{2}{*}{ Statistic } & \multicolumn{2}{|c|}{ Panel A: Expiration days } & \multicolumn{2}{|c|}{ Panel B: Expiration weeks } \\
\hline & & $\begin{array}{l}\text { Expiration } \\
\text { group }\end{array}$ & $\begin{array}{c}\text { Comparison } \\
\text { group }\end{array}$ & $\begin{array}{l}\text { Expiration } \\
\text { group }\end{array}$ & $\begin{array}{c}\text { Comparison } \\
\text { group }\end{array}$ \\
\hline \multirow{7}{*}{$\begin{array}{l}\text { June } 2001 \\
\text { to } \quad \text { May } \\
2009 \\
\text { June } 2001\end{array}$} & Number of days & 108 & 216 & 324 & 854 \\
\hline & Mean & 0.318 & 0.271 & -0.059 & 0.037 \\
\hline & Standard deviation & 1.231 & 1.072 & 1.417 & 1.392 \\
\hline & Median & 0.345 & 0.086 & 0.043 & 0.071 \\
\hline & $t$-test & \multicolumn{2}{|c|}{$2.89 *$} & \multicolumn{2}{|c|}{-0.92} \\
\hline & $\mathrm{W}$-test & \multicolumn{2}{|c|}{$2.37^{*}$} & \multicolumn{2}{|c|}{1.18} \\
\hline & Number of days & 54 & 108 & 162 & 427 \\
\hline \multirow{7}{*}{$\begin{array}{l}\text { to } \\
2005\end{array}$} & Mean & 0.0186 & 0.0182 & -0.174 & 0.123 \\
\hline & Standard deviation & 1.173 & 0.933 & 1.371 & 1.339 \\
\hline & Median & 0.438 & 0.086 & -0.235 & 0.204 \\
\hline & $t$-test & \multicolumn{2}{|c|}{$-2.05^{*}$} & \multicolumn{2}{|c|}{$-2.32^{*}$} \\
\hline & $\mathrm{W}$-test & \multicolumn{2}{|c|}{$1.99 *$} & \multicolumn{2}{|c|}{$2.11^{*}$} \\
\hline & Number of days & 54 & 108 & 162 & 427 \\
\hline & Mean & 0.241 & 0.209 & 0.028 & -0.043 \\
\hline \multirow{4}{*}{$\begin{array}{lr}\text { June } & 2005 \\
\text { to } & \text { May } \\
2009 & \end{array}$} & Standard deviation & 1.221 & 1.148 & 1.427 & 1.291 \\
\hline & Median & 0.376 & 0.142 & 0.081 & -0.045 \\
\hline & $t$-test & \multicolumn{2}{|c|}{$1.97 *$} & \multicolumn{2}{|c|}{0.82} \\
\hline & $\mathrm{W}$-test & \multicolumn{2}{|c|}{$2.19 *$} & \multicolumn{2}{|c|}{1.01} \\
\hline
\end{tabular}

Note: The terms "Mean" and "Median" denote open-to-close mean and median adjusted trading volume, respectively. The term "Standard deviation" denotes the standard deviation of open-to-close adjusted trading volume.

* indicates that a one-sided pooled $\boldsymbol{t}$-test or Wilcoxon rank sum test (W-test) is able to reject the hypothesis that the daily trading volume at expiration is not higher than for the comparison group at the 5\% level of significance. 
Panel B, in Table 2, presents the mean and median daily return and volatility for the NSE Nifty index for expiration weeks and comparison weeks. For the complete sample period and the latter subperiod, no statistical difference is shown between the expiration and comparison sample for either the average daily return or the volatility. However, for the first sub-period, the $t$-test and W-test indicates a significant difference for the average return between the samples. The return was on average -0.174 for expiration weeks, compared with $0.123 \%$ for the comparison weeks. This finding supports the notion that the abnormally high trading volume for the expiration weeks, during the first sub-period, resulted from the early unwinding of long positions in the cash market. This in turn caused a downward pressure on the prices of the stocks.

Table -3: Daily price range between high and low values on the NSE Nifty Index

\begin{tabular}{|c|c|c|c|c|c|}
\hline \multirow{2}{*}{ Period } & \multirow{2}{*}{ Statistic } & \multicolumn{2}{|c|}{ Panel A: Expiration days } & \multicolumn{2}{|c|}{ Panel B: Expiration weeks } \\
\hline & & $\begin{array}{l}\text { Expiration } \\
\text { group }\end{array}$ & $\begin{array}{l}\text { Comparison } \\
\text { group }\end{array}$ & $\begin{array}{l}\text { Expiration } \\
\text { group }\end{array}$ & $\begin{array}{l}\text { Comparison } \\
\text { group }\end{array}$ \\
\hline \multirow{7}{*}{$\begin{array}{l}\text { June } 2001 \\
\text { to May } \\
2009 \\
\text { June } 2001\end{array}$} & Number of days & 108 & 216 & 324 & 854 \\
\hline & Mean & 1.481 & 1.434 & 1.618 & 1.521 \\
\hline & Standard deviation & 0.911 & 0.929 & 0.963 & 0.971 \\
\hline & Median & 1.215 & 1.245 & 1.281 & 1.238 \\
\hline & $t$-test & \multicolumn{2}{|c|}{0.67} & \multicolumn{2}{|c|}{1.33} \\
\hline & $\mathrm{W}$-test & \multicolumn{2}{|c|}{0.78} & \multicolumn{2}{|c|}{1.42} \\
\hline & Number of days & 54 & 108 & 162 & 427 \\
\hline to May & Mean & 1.187 & 0.918 & 1.392 & 1.178 \\
\hline \multirow[t]{6}{*}{2005} & Standard deviation & 0.981 & 0.759 & 0.948 & 0.788 \\
\hline & Median & 0.877 & 0.743 & 1.018 & 0.925 \\
\hline & $t$-test & \multicolumn{2}{|c|}{$\begin{array}{l}1.59^{*} \\
2.08 *\end{array}$} & \multicolumn{2}{|c|}{$1.77^{*}$} \\
\hline & $\mathrm{W}$-test & \multicolumn{2}{|c|}{$2.08^{*}$} & \multicolumn{2}{|c|}{$1.84^{*}$} \\
\hline & Number of days & 54 & 108 & 162 & 427 \\
\hline & Mean & 1.645 & 1.679 & 1.671 & 1.633 \\
\hline \multirow{4}{*}{$\begin{array}{l}\text { June } 2005 \\
\text { to May } \\
2009\end{array}$} & Standard deviation & 0.879 & 0.910 & 0.888 & 0.955 \\
\hline & Median & 1.333 & 1.489 & 1.418 & 1.379 \\
\hline & $t$-test & \multicolumn{2}{|c|}{-0.57} & \multicolumn{2}{|c|}{0.59} \\
\hline & $\mathrm{W}$-test & \multicolumn{2}{|c|}{-0.92} & \multicolumn{2}{|c|}{-0.51} \\
\hline
\end{tabular}

Note: The terms "Mean" and "Median" denote open-to-close mean and median adjusted trading volume, respectively. The term "Standard deviation" denotes the standard deviation of open-to-close adjusted trading volume.

* indicates that a one-sided pooled $\boldsymbol{t}$-test or Wilcoxon rank sum test (W-test) is able to reject the hypothesis that the daily trading volume at expiration is not higher than for the comparison group at the $5 \%$ level of significance.

Table 3 summarizes the mean and median daily range between high and low values for expiration and for comparison days. Panel-A provides the results taking into consideration for the expiration days and comparison days, while panel- $B$ reports the findings of mean, median and volatility for the for the expiration week and corresponding comparison week. It is observed that for the entire time period of June 2001 to May 2009, the average price range on expiration day was $3.27 \%$ higher (as against comparison day) and on expiration week the mean price range was $6.37 \%$ higher in relation to comparison week. Further, the volatility of price range (measured by standard deviation) is relatively lower for the expiration period both in terms of expiration day and expiration week. Similar observation regarding volatility during expiration at NSE Nifty is also observed for the first sub-period, while during the second cub-period the volatility of price range during expiration day is higher than the comparison day and also the same for the expiration week against the comparison week.

For the second sub-period, the mean price range in expiration day and expiration week was relatively lesser than that of the comparison group, while in the first sub-period (June 2001 to May 2005 ) the average price range on expiration day/week is found to be higher than the comparison group. Significantly different values of t-test and $\mathrm{W}$-test are only indicated for the first sub-period, which are found to have been significantly higher for expiration days than for comparison days. In 
sum, the results for the complete sample period and second sub-period suggest that price distortions did not occur on the expiration day or during the expiration week. However, for the first sub-period, evidence exists suggesting that expiration days and weeks were characterized by abnormal volatility.

Table-4: Mean price reversals (in \%) and percentage of days with reversals on the NSE Nifty

\begin{tabular}{lllll}
\hline \multicolumn{1}{c}{ Period } & \multicolumn{1}{c}{ Statistics } & \multicolumn{1}{c}{$\begin{array}{c}\text { Expiration } \\
\text { days }\end{array}$} & Comparison days & t-test \\
\hline & Type 0 reversal & -0.195 & -0.183 & \\
June 2001 to & Type 1 reversal & 0.936 & 0.843 & -0.27 \\
May 2009 & Type 2 reversal & 0.887 & 0.791 & \\
& Percentage of reversals & 52 & 56 & -1.34 \\
June 2001 to & Type 0 reversal & -0.272 & -0.008 & \\
May 2005 & Type 1 reversal & 0.732 & 0.604 & \\
& Type 2 reversal & 0.739 & 0.671 & \\
& Percentage of reversals & 57 & 57 & 0.73 \\
June 2005 to & Type 0 reversal & -0.142 & -0.235 & \\
& Type 1 reversal & 1.074 & 0.911 & \\
& Type 2 reversal & 0.923 & 0.854 & \\
& Percentage of reversals & 48 & 47 &
\end{tabular}

Note: The term "Percentage of reversals" denotes the percentage of days with sequential price changes that have opposite signs. The t-test evaluates whether Type 0 reversals are statistically larger on expiration days than on comparison days.

\subsection{Price Reversals}

Table-4 presents the Mean of price reversals of type 0 , type 1 and type 2 reversals for both expiration day and comparison days along with percentage of days with reversals on the NSE Nifty. To further test whether a price effect existed or not, the degree to which prices reversed was measured. A price reversal is assumed to occur when an abnormal price change takes place, which is not motivated by the arrival of new information. Greater price reversals at expiration than normal indicate that expiration causes price distortions. The mean type 0 price reversal for the complete sample period is given in column 1 of Table 4. A positive value for REV0 indicates price reversal, whereas a negative value indicates continuation. The type 0 results indicate continuation for days following both expiration and comparison days, with no significant difference between the days. The type 1 and type 2 reversals report somewhat higher mean returns for the expiration sample than for the comparison sample. Table 4 also shows the percentage of days that experienced a price reversal and shows that reversals were about as common for the expiration as for the comparison sample with $52 \%$ and $56 \%$, respectively. During the first sub-period, the percentage of days that experienced a price reversal is $57 \%$ for expiration days and comparison days, while for the second sub-period the percentage of days that experienced a price reversal is about $47 \%$ for expiration days and comparison days. Overall, the results suggest that price reversals did not occur at expiration. 


\section{Summary and Conclusions}

This study examined potential expiration effects on the NSE Nifty index by comparing the trading volume and return process on expiration days and during expiration weeks with a set of comparison days and comparison weeks. The period of analysis covers expirations from June 2001 to May 2009. The complete sample period was divided into two equal sub-periods. The major findings of this study are: firstly, for the complete sample period as well as for the two sub-periods, the evidence indicates that the trading volume on expiration days and in expiration weeks was significantly larger than on comparison days and during comparison weeks. Secondly, the results suggest that there were no price distortions on the expiration day or during the expiration week for the complete sample period and the second sub period.

For the first sub-period, however, evidence suggesting that expiration days and weeks experienced higher volatility than normal does exist. In addition, during the first sub-period, expiration weeks experienced significantly lower returns than comparison weeks. This was in accordance with the perception that the early unwinding of long positions in the cash resulted in a downward pressure on the prices of stocks. However, during the first sub-period, the mean price reversal was not greater on days following expiration days than on comparison days. This was also the case for the complete sample period and the second sub-period. The results for the complete sample period are consistent with the following: the significantly higher trading volumes on the expiration day and during the expiration week suggest that arbitrage activity took place and that positions were unwound at and before the actual expiration. However, the unwinding of arbitrage positions failed to cause any price distortions at expiration since the longer settlement period that is used for the NSE Nifty index helped to curb sharp price movements, by reducing the number of positions being unwound at any one time. Further, the findings of the study suggest that there is existence of expiration effect in Indian stock market with relation to derivative trading. The investors and the speculators in specific can profit out of arbitrage possibilities arising from the temporary mismatch in prices in cash and derivative market. Although the settlement procedure for the NSE Nifty index calls for an investigation of the entire expiration day rather than a short interval, it would be interesting to investigate higher frequency data to reveal whether the intraday trading pattern differs across expiration days and comparison days. Unfortunately, this was not possible in this study since high frequency data is not obtainable.

\section{Refrences}

Alkeback, P. and N. Hagelin (2004): Expiration day effects of index futures and options: Evidence from a market with a long settlement period, Applied Financial Economics, 14(6):385-396

Bacha, O. and Villa, F. (1993): Multi-Market Trading and Price-Volume Relationship: The Case of the Nikkei Stock Exchange Futures Markets, Working Paper-9, Boston University

Bodla, B. S. and Kiran, J. (2008): Equity Derivatives in India: Growth Pattern and Trading Volume Effects, ICFAI Journal of Derivatives Markets, 5(1):62-82

Brennan, M.J., \& Schwartz, E.S. (1990): Arbitrage in stock index futures, Journal of Business, 63:7-31.

Chamberlain, T.W.( 1989): Maturity Effects in Futures Markets: Some Evidence from the City of London, Scottish Journal of Political Economy, 36(1):90-95.

Chamberlain, T.W., Cheung S.C., \& Kwan, C.C.Y. (1989): Expiration-day effects of index futures and options: Some Canadian evidence, Financial Analysts Journal, 21: 67-71.

Chen, C., \& Williams, J. (1994): Triple-witching hour, the change in expiration timing, and stock market reaction, Journal of Futures Markets, 14:275-292.

Cheng, L.T.W., Fung J.K.W., \& Pang, C. (1998): Early unwinding strategy in index options-futures arbitrage, Journal of Financial Research, 21:447-467.

Chuang, C.(2003): International Information Transmissions between Stock Index Futures and Spot Markets: The Case of Futures Contracts Related to Taiwan Index, Journal of Management Science, 19(1):51-78.

Day, T.E., \& Lewis, C.M. (1988): The behavior of the volatility implicit in the prices of stock index options, Journal of Financial Economics, 22:103-122. 
Diz, F., \& Finucane, T.J. (1998): Index option expirations and market volatility, Journal of Financial Engineering, 7: $1-23$.

Edwards, F.R. (1988): 'Futures trading and cash market volatility: Stock index and interest rate futures, The Journal of Futures Markets, 8:421-439.

Edwards, F.R. (1988): "Futures trading and cash market volatility: Stock index and interest rate futures, Journal of Futures Markets, 8:421-439

Hancock, G.D. (1993): Whatever happened to the triple witching hour?, Financial Analysts Journal, 11:66- 72.

Herbst, A.F. and Maberly, E.D. (1990): Stock index futures, expiration day volatility and the "special Friday opening: A note, Journal of Futures Markets, 10:323-325.

Illueca, M. and Lafuente, J. A. (2006): New Evidence On Expiration-Day Effects Using Realized Volatility: An IntraDay Analysis For The Spanish Stock Exchange, Working Paper EC-05, Department of Finance and Accounting, Universitat Jaume I, Campus del Riu Sec, Castellón, Spain: 19.

Jain, P., \& Joh, G. (1988): The dependence between hourly prices and trading volume, Journal of Financial and Quantitative Analysis, 23:269-284.

Jindal, K. and Bodla, B. S. (2007): Expiration Day Effect of Stock Derivatives on the Volatility, Return and Trading Volume of Underlying Stocks, ICFAI Journal of Derivatives Markets, 4(2):46-57.

Karolyi,A.G. (1996): Stock Market volatility around expiration days in Japan, Journal of Derivatives, 4(4):23-43.

Lien, Donald and Yang, Li (2005): Availability and settlement of individual stock futures and options expirationday effects: evidence from high-frequency data, The Quarterly Review of Economics and Finance ,45(4):730-747.

Maniar, Hiren M., Bhatt, Rajesh. And Maniyar, Dharmesh M. (2007): Expiration Hour Effect of Futures and Options Markets on Stock Market-A Case Study on NSE (National Stock Exchange of India), Annual Conference on Pacific Basin Finance, Economics, Accounting, and Management, Queensland University of Technology, Australia.

Merrick, J.J. Jr (1989): Early unwindings and rollovers of stock index futures arbitrage programs: Analysis and implications for predicting expiration day effects, Journal of Futures Markets, 9:101-111.

Niemeyer, J., \& Sandås, P. (1993): An empirical analysis of the trading structure at the Stockholm Stock Exchange, Journal of Multinational Financial Management, 3:63.101.

Parkinson, M. (1980): The extreme value method for estimating the variance of the rate of return, Journal of Business, 53:61.65.

Pope, P.F. and Yadav, P.K. (1992): The impact of option expiration on underlying stocks: The UK evidence, Journal of Business Finance and Accounting, 19(3):329-344.

Sarangi, S.P. and Patnaik, U.S. (2007): Futures Trading and Volatility: A Case of S\&P CNX Nifty Stocks and Stock Futures, ICFAI Journal of Derivatives Markets, 4(4):64-87

Schlag, C. (1996): Expiration day effects of stock index derivatives in Germany, European Financial Management, 1:69-95.

Schwert, W.G. (1990): Stock volatility and the crash of '87, Review of Financial Studies, 3:77-102.

Stoll, H.R. (1988): Index futures, program trading, and stock market procedures, Journal of Futures Markets, 8:391-412.

Stoll, H.R. and Whaley, R.E. (1990): Stock market structure and volatility, The Review of Financial Studies, 3: 3771.

Stoll, H.R., \& Whaley, R.E. (1987): Program trading and expiration-day effects, Financial Analysts Journal, 17:1628.

Stoll, H.R., \& Whaley, R.E. (1991): Expiration-day effects: What has changed? Financial Analysts Journal,16:58-71.

Stoll, H.R., \& Whaley, R.E. (1997): Expiration-day effects of the all ordinaries share price index futures: Empirical evidence and alternative settlement procedures, Australian Journal of Management, 22:139- 174.

Swidler, S., Schwartz L., \& Kristiansen, R. (1994): Option expiration day effects in small markets: Evidence from the Oslo Stock Exchange, Journal of Financial Engineering, 3:177-195.

Thenmozhi, M. and Sony, T.M. (2004): Impact of index derivatives on S\&P CNX Nifty volatility: Information efficiency and expiration effects, The ICFAI Journal of Applied Finance, 8(8):36-55. 